\title{
Short Communication: Effect of urban greening and land use on air pollution in Chelyabinsk, Russia
}

\author{
TATYANA G. KRUPNOVA ${ }^{1, \boldsymbol{v}}$, OLGA V. RAKOVA ${ }^{1}$, ANNA L. PLAKSINA ${ }^{2}$, SVETLANA V. GAVRILKINA ${ }^{3}$, \\ EVGENY O. BARANOV ${ }^{1}$, ANTON D. ABRAMYAN ${ }^{1}$ \\ ${ }^{1}$ Department of Ecology, Management of Natural Resources and Chemical Engineering, Institute of Natural Sciences and Mathematics, South Ural State \\ University. 76, Lenin prospekt, 454080 Chelyabinsk, Russia. Tel.: +7-9642444419, `email: krupnovatg@ susu.ru \\ ${ }^{2}$ Department of Geoecology and Environmental Management, Faculty of Ecology, Chelyabinsk State University. 129 Kashirin Brothers street, 454001 \\ Chelyabinsk, Russia \\ ${ }^{3}$ South Urals Federal Research Center of Mineralogy and Geoecology of the Urals Branch of the Russian Academy of Sciences. Ilmen reserve, 456317 \\ Miass, Russia
}

Manuscript received: 3 February 2020. Revision accepted: 23 May 2020.

\begin{abstract}
Krupnova TG, Rakova OV, Plaksina AL, Gavrilkina SV, BaranovEO, Abramyan AD. 2020. Effect of urban greening and land use on air pollution in Chelyabinsk, Russia. Biodiversitas 21: 2716-2720. Chelyabinsk is a major industrial Russian city that faces diverse environmental issues, the most important of which is air emissions. The primary sources of air pollution in Chelyabinsk are industry (concrete product plants, ferrous and nonferrous metallurgy such as zinc production plants, and pulp production), thermal power stations, and transport. People have known that trees can help to reduce air pollutants for a long time. We studied 8 zones within a radius of one kilometer from state air pollution monitoring stations. Eight land-use types such as industrial category, residential category, natural and semi-natural broadleaved vegetation, natural and semi-natural coniferous vegetation, broadleaved forest, coniferous forest, artificial broadleaved vegetation, and artificial coniferous vegetation, were obtained. The response of air pollution to land-use and urban greening was analyzed. Analysis results showed that there was no correlation between industrial and residential categories of land-using and concentrations of the most dangerous air pollutants in Chelyabinsk (formaldehyde, hydrogen fluoride, and nitrogen dioxide). The dominant factor affecting urban air quality was urban greening.
\end{abstract}

Keywords: Land-use and land-cover analysis, urban air quality, urban vegetation, phytoremediation

\section{INTRODUCTION}

Air pollution is one of the most dangerous factors that influenced human health. There are many primary and secondary sources of air pollution in industrial cities. The amount and source of emissions, local topography, prevailing meteorological conditions, land use, and land cover have a large effect on air pollution in a particular city area. It is well known that urban greening and urban forests can improve air pollution (Abhijith et al. 2017, Taleghani et al. 2020, Xing et al. 2020). The researchers considered the urban greening as the lungs of cities (Xu et al. 2020). Urban trees accumulate the airborne fine particulate matter, PM2.5 (Zhou et al. 2019, Han et al. 2020). It was shown that trees affect nitrogen oxides $\left(\mathrm{NO}_{\mathrm{x}}\right)$, benzo(a)pyrene, polycyclic aromatic hydrocarbons (PAHs), and ozone $\left(\mathrm{O}_{3}\right)$ concentrations (Klingberg et al. 2017, Buccolieri et al. 2018). According to Nowak et al. (2014) trees remove 651,000 tonnes of air pollutants per year. However, there is discussion about tree roles in decreasing local air pollutant concentrations. Recent studies have shown that traditional urban greening schemes may not work well. Tall trees and large buildings form street canyons in city conditions (Abhijith et al. 2017). Trees actually make pollution more concentrated. Planting tall trees in street with traffic is not effective strategy according to air pollution modelling
(Santiago et al. 2017).

Chelyabinsk is typical industrial Russian city. It is the capital of the South Ural region. Chelyabinsk is a major industrial center, including metallurgical, machinebuilding, metalworking enterprises, instrument-making factories, food, chemical, and light industry production facilities. There is heavy smog in Chelyabinsk urban area during adverse weather conditions such as low wind speed and no rain. Residents of Chelyabinsk worry about 'black sky' air pollution. The city has 8 stationary stations and some mobile laboratories for the study of quality of air pollution levels. The laboratories are used for the routine of observation on the residential areas of Chelyabinsk, and on the border of sanitary-protective zones of different plants.

The most dangerous pollutants of Chelyabinsk are formaldehyde, phenol, sulfide hydrogen $\left(\mathrm{H}_{2} \mathrm{~S}\right)$, nitrogen oxides (NOx), ammonia $\left(\mathrm{NH}_{3}\right)$, carbon monoxide (CO), hydrogen fluoride (HF) and common particulate matter (PM). They affect human health and vegetation such as epiphytic lichens (Krupnova et al. 2017). The health effects of the common toxic air pollutants of Chelyabinsk are different. Short-term effects include headache, runny nose, nausea, and difficulty breathing. Inhalation of nitrogen oxides can lead to pulmonary edema. Formaldehyde causes cancer. Signs of hydrogen fluoride chronic exposure include conjunctivitis, bronchitis, pneumonia, pneumosclerosis. 
The PM health effects cardiovascular morbidity, respiratory diseases, and lung cancer (Theophanides et al. 2011).

In this study, we assessed the relationships urban land use, urban greening, and air pollution inside Chelyabinsk territory. We tried to understand how they influence the local concentrations of toxic air pollutants. In this study, we analyse the data of air monitoring stations and examine land-use cover and greening in proximity to air quality monitors. Studies presenting the influence of vegetation and land use on air pollution of Chelyabinsk have not been found. We used GIS technology to demonstrate the major factors that affect air pollution levels in the Chelyabinsk. The aim of our study was to improve understanding of the effect of urban land use and vegetation on air quality of Chelyabinsk.

\section{MATERIALS AND METHODS}

\section{Study area}

The study was conducted in Chelyabinsk, situated on the border of the Urals and Siberia, Russia Federation. For this study we selected eight sites. The location of the measurement sites is shown in Fig. 1. These sites are stationary stations of the state monitoring of atmospheric air in Chelyabinsk. From 2016 to 2019, the data of state monitoring of the state of atmospheric air are available on the public website of the Ministry of Ecology of the Chelyabinsk Region (mineco174). Table 1 shows the characteristics of the investigated sites. Land use was studied within a radius of one kilometer from state air pollution monitoring stations.

\section{Procedures}

\section{Land cover mapping}

We studied zones within a radius of one kilometer from state air pollution monitoring stations which we chose as investigated sites. We used 4 satellite images at $0.7 \mathrm{~m}$ of spatial resolution from summers 2016-2019. We used satellite images of different years, google street image, and field verification for land-use cover mapping of zones around investigated sites. There were no significant changes in vegetation between different years in selected zones. We created maps using MapInfo Pro.

We used the method of visual interpretation using direct features (texture, color, structure, and image shape) to identify objects in satellite images. To identify the effects of air emissions we chose to use the simplified set of 8 land-use categories shown in Table 2. Chelyabinsk is characterized by green areas inside and around the city consisting of a heterogeneous scheme combining individual gardens, courtyard greening, greening of industrial areas, public parks, 14 urban forests. It should note that there is no official or any other inventory of trees in Chelyabinsk. There are a lot of industrial areas. Private housing construction preserved in Chelyabinsk along with modern multi-stored buildings.

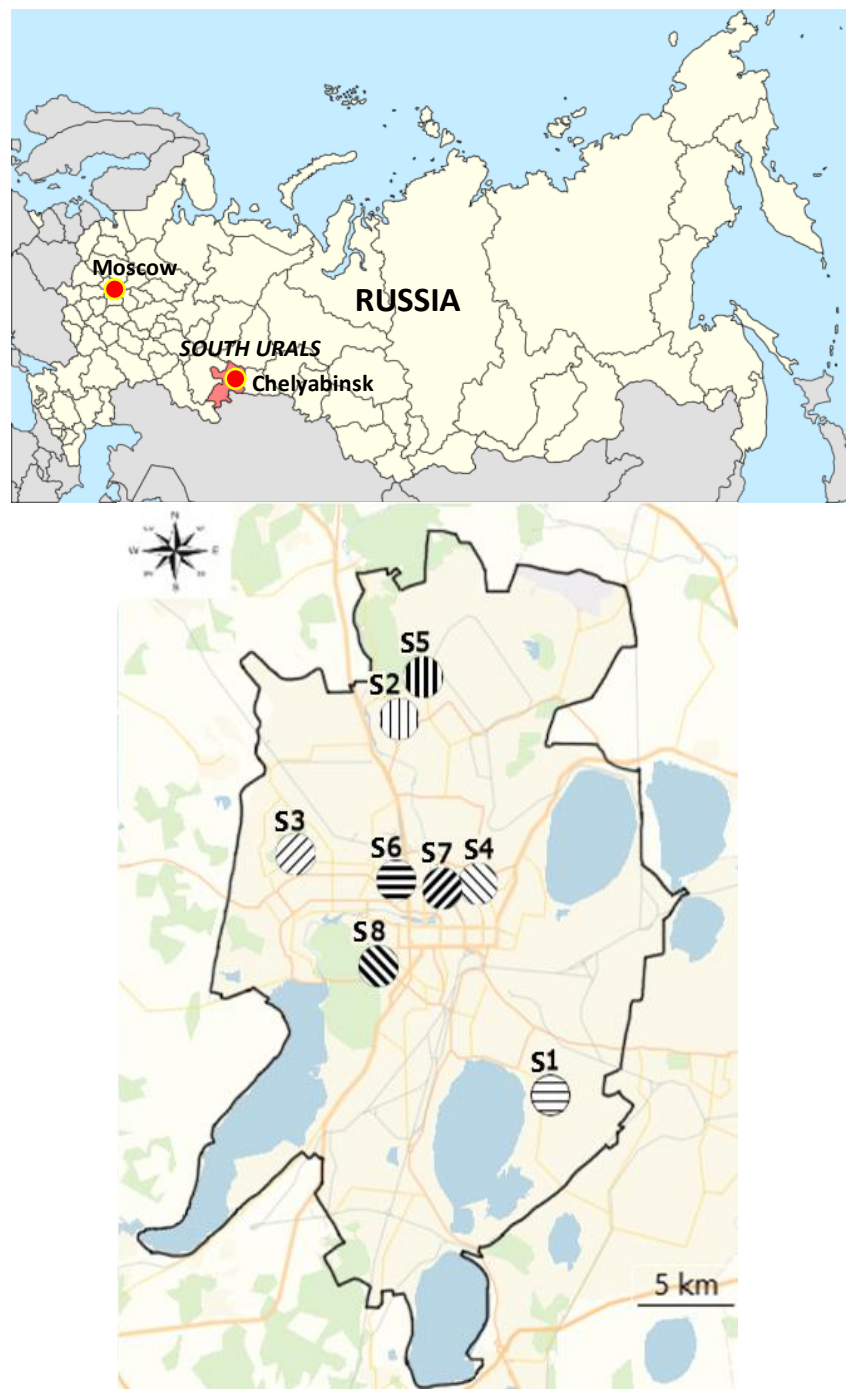

Figure 1. Location of investigated sites in Chelyabinsk, Russia

Table 1. Description of investigated sites

\begin{tabular}{|c|c|c|c|}
\hline \multirow{2}{*}{ Site } & \multicolumn{2}{|c|}{ Location } & \multirow{2}{*}{ Sources of pollution* } \\
\hline & Latitude $(\mathbf{N})$ & Longitude (E) & \\
\hline S1 & $55^{\circ} 10^{\prime} 03.05^{\prime \prime}$ & $61^{\circ} 49^{\prime} 26.30^{\prime \prime}$ & Chelyabinsk Pipe Plant, transport \\
\hline $\mathrm{S} 2$ & $55^{\circ} 25^{\prime} 46.22^{\prime \prime}$ & $61^{\circ} 37^{\prime} 91.42^{\prime \prime}$ & Chelyabinsk Metallurgical Plant \\
\hline S3 & $55^{\circ} 19^{\prime} 93.52^{\prime \prime}$ & $61^{\circ} 30^{\prime} 72.51^{\prime \prime}$ & It is residential area. There were no specific sources \\
\hline S4 & $55^{\circ} 18^{\prime} 32.79^{\prime \prime}$ & $61^{\circ} 43^{\prime} 31.56^{\prime \prime}$ & Chelyabinsk Electrometallurgical Integrated Plant \\
\hline S5 & $55^{\circ} 26^{\prime} 73.86^{\prime \prime}$ & $61^{\circ} 38^{\prime} 86.71^{\prime \prime}$ & Chelyabinsk Metallurgical Plant \\
\hline S6 & $55^{\circ} 18^{\prime} 52.24^{\prime \prime}$ & $61^{\circ} 38^{\prime} 21.03^{\prime \prime}$ & Chelyabinsk Zinc Plant, transport \\
\hline S7 & $55^{\circ} 18^{\prime} 30.64^{\prime \prime}$ & $61^{\circ} 41^{\prime} 39.51^{\prime \prime}$ & Chelyabinsk Electrometallurgical Integrated Plant, Chelyabinsk Zinc Plant \\
\hline S8 & $55^{\circ} 15^{\prime} 31.96^{\prime \prime}$ & $61^{\circ} 36^{\prime} 62.39^{\prime \prime}$ & It is residential area. There were no specific sources \\
\hline
\end{tabular}

Note: * plant is located on the distance less than $3 \mathrm{~km}$ 
Table 2. Land-use categories used in this study

\begin{tabular}{|c|c|c|}
\hline Category & Abbreviation & Description \\
\hline Industrial & Ind & $\begin{array}{l}\text { It is an area of industrial } \\
\text { enterprises and thermal power } \\
\text { stations. It can serve as a source of } \\
\text { various anthropogenic emissions } \\
\text { of gases such as benzo(a)pyrene, } \\
\text { formaldehyde, sulfur dioxide, } \\
\text { nitrogen oxides, carbon monoxide, } \\
\text { hydrogen fluoride, and common } \\
\text { particulate matter }\end{array}$ \\
\hline Residential & $\mathrm{R}$ & $\begin{array}{l}\text { It is an area of private house } \\
\text { location. It uses fuel such as } \\
\text { wood and coal for heating }\end{array}$ \\
\hline $\begin{array}{l}\text { Natural and } \\
\text { semi-natural } \\
\text { broadleaved } \\
\text { vegetation }\end{array}$ & NBV & $\begin{array}{l}\text { It is vegetation formation composed } \\
\text { principally of broadleaved trees } \\
\text { by natural origin in urban areas, } \\
\text { such as public urban parks, urban } \\
\text { natural areas, and street tree }\end{array}$ \\
\hline $\begin{array}{l}\text { Natural and } \\
\text { semi-natural } \\
\text { coniferous } \\
\text { vegetation }\end{array}$ & $\mathrm{NCV}$ & $\begin{array}{l}\text { It is vegetation formation composed } \\
\text { principally of coniferous trees by } \\
\text { natural origin in urban areas, such } \\
\text { as public urban parks, urban } \\
\text { natural areas, and street tree }\end{array}$ \\
\hline $\begin{array}{l}\text { Broadleaved } \\
\text { forest }\end{array}$ & $\mathrm{BF}$ & $\begin{array}{l}\text { It is principally broadleaved } \\
\text { urban forests }\end{array}$ \\
\hline $\begin{array}{l}\text { Coniferous } \\
\text { forest }\end{array}$ & $\mathrm{CF}$ & $\begin{array}{l}\text { It is principally coniferous urban } \\
\text { forests }\end{array}$ \\
\hline $\begin{array}{l}\text { Artificial } \\
\text { broadleaved } \\
\text { vegetation }\end{array}$ & $\mathrm{ABV}$ & $\begin{array}{l}\text { It is vegetation formation composed } \\
\text { principally of broadleaved trees } \\
\text { by anthropogenic origin in urban } \\
\text { areas, such as public urban parks, } \\
\text { urban natural areas, and street } \\
\text { tree }\end{array}$ \\
\hline $\begin{array}{l}\text { Artificial } \\
\text { coniferous } \\
\text { vegetation }\end{array}$ & $\mathrm{ACV}$ & $\begin{array}{l}\text { It is vegetation formation composed } \\
\text { principally of coniferous trees } \\
\text { by anthropogenic origin in urban } \\
\text { areas, such as public urban parks, } \\
\text { urban natural areas, and street } \\
\text { tree }\end{array}$ \\
\hline
\end{tabular}

\section{Data analysis}

\section{Land use cover calculation}

The areas of each land-use type were calculated using MapInfo Pro. We calculated the cover of each land-use type in $\%$ of total area of zones around investigated sites. Also, we calculated the total broadleaved and coniferous urban greening - TBG and TCG, respectively:

$$
\begin{aligned}
& T B G_{s} \%=N B V_{s} \%+B F_{s} \%+A B V_{s} \%, \\
& T C G_{s} \%=N C V_{s} \%+C F_{v} \%+A C V_{s} \% .
\end{aligned}
$$

\section{Air pollution data}

Concentrations of key pollutants such as formaldehyde, $\mathrm{HF}, \mathrm{H}_{2} \mathrm{~S}, \mathrm{CO}$, phenol, $\mathrm{NH}_{3}, \mathrm{NO}, \mathrm{NO}_{2}$, and common particulate matter (PM) were obtained the public website of the Ministry of Ecology of the Chelyabinsk Region (mineco174). We analyzed data during 2016-2019. Data on the site is not posted every day, but once every few days. In just 4 years, data for $\mathrm{N}_{\text {total }}=1102$ days were analyzed. For each pollutant, the number of days was chosen with the excess of the established maximum permissible concentrations (MPC) according to Russian Federation norm at the $\mathrm{i}$-th investigated site, $\mathrm{N}_{\mathrm{i}}(\mathrm{i}=1,2 \ldots 8)$. For each pollutant in each site, times of exceeded MPC, n, \% were calculated using the equation:

$$
n_{s} \%=N i / N \text { total } * 100 \% \text {, }
$$

Where: Ni is the number of days (times out of 1102 days during 2016-2019) with the excess of MPC at the i-th investigated site, $\mathrm{N}_{\text {total }}$ is 1102 days for which there were data on air pollutant monitoring posted the public website.

\section{RESULTS AND DISCUSSION}

\section{Land-use cover}

Sites S3, S6, and S8 did not have industrial areas at a distance of 1 kilometer. With the exception of Site S3, there was residential area within a radius of one kilometer from sites. Site S1 was characterized by maximum residential area cover $-33.3 \%$. Sites had different greening situation. Table 3 shows that most sites were dominated by two greening categories: natural and semi-natural broadleaved vegetation and artificial broadleaved vegetation.

\section{Air pollution}

Table 4 shows times during 2016-2019 when exceeds of MPC for the air pollutants were observed.

It should be noted that all pollutants can be divided into two groups according to times of exceeded MPC. For HF, $\mathrm{H}_{2} \mathrm{~S}, \mathrm{CO}$, phenol, $\mathrm{NH}_{3}, \mathrm{NO}$, and common particulate matter the number of days with exceeded MPC for all sites did not exceed 5 percent of the total number of days. The largest times of MPC excess were found for formaldehyde (up to $28.2 \%$ of all observation days), $\mathrm{HF}(14.1 \%$ and $11.3 \%$ days in Sites $\mathrm{S} 1$ and $\mathrm{S} 2$, responsibility), and $\mathrm{NO}_{2}$ (up to $13.4 \%$ of days).

Table 3. Land-use covers of zones within a radius of one kilometer from state air pollution monitoring stations

\begin{tabular}{lllllllll}
\hline \multirow{2}{*}{ Site } & \multicolumn{10}{c}{ Land-use cover, \% } \\
\cline { 2 - 10 } & \multicolumn{1}{c}{$\mathbf{R}$ N } & NBV & NCV & BF & CF & ABV & ACV \\
\hline S1 & 7.4 & 33.3 & 11.85 & 0 & 0 & 0.1 & 6 & 0 \\
S2 & 5.8 & 15 & 0 & 0.35 & 0 & 0 & 22.6 & 0 \\
S3 & 0 & 0.78 & 27.55 & 0 & 0 & 0.67 & 10.6 & 8.2 \\
S4 & 2.52 & 18.4 & 1.94 & 0 & 1.35 & 0 & 19.4 & 0.1 \\
S5 & 3.4 & 0 & 38.8 & 0.02 & 4.02 & 1.12 & 14.9 & 5.04 \\
S6 & 0 & 16.4 & 0 & 0.37 & 0 & 0 & 16.5 & 0 \\
S7 & 4.64 & 9.45 & 9.7 & 0.01 & 0 & 0 & 17.2 & 0 \\
S8 & 0 & 0.38 & 7.08 & 0.24 & 0.39 & 3.32 & 9.7 & 21.8 \\
\hline
\end{tabular}


Table 4. Times of exceeded MPC of the air pollutants during 2016-2019

\begin{tabular}{|c|c|c|c|c|c|c|c|c|c|}
\hline \multirow{2}{*}{ Site } & \multicolumn{9}{|c|}{$\mathbf{N}$, days (n\%) } \\
\hline & Formaldehyde & $\mathrm{NO}_{2}$ & HF & NO & CO & Phenol & $\mathrm{H}_{2} \mathrm{~S}$ & $\mathrm{NH}_{3}$ & PM \\
\hline S1 & $25(2.3)$ & $2(0.2)$ & $124(11.3)$ & $1(0.1)$ & $1(0.1)$ & $15(1.4)$ & n.o. & n.o. & n.o. \\
\hline $\mathrm{S} 2$ & $311(28.2)$ & $72(6.5)$ & $155(14.1)$ & $9(0.8)$ & $1(0.1)$ & $47(4.3)$ & n.o. & $2(0.2)$ & $1(0.1)$ \\
\hline S3 & $14(1.3)$ & n.o. & n.o. & n.o. & $3(0.3)$ & $4(0.4)$ & n.o. & n.o. & n.o. \\
\hline S4 & $166(15)$ & $126(11.4)$ & n.o. & n.o. & n.o. & $7(0.6)$ & n.o. & n.o. & $1(0.1)$ \\
\hline S5 & 13(1.2) & $6(0.5)$ & n.o. & $3(0.3)$ & $13(1.2)$ & $10(0.9)$ & $10(0.9)$ & n.o. & n.o. \\
\hline S6 & 184(16.7) & 141(12.8) & $1(0.9)$ & n.o. & $7(0.6)$ & $11(1)$ & $1(0.1)$ & $5(0.5)$ & n.o. \\
\hline S7 & $258(23.4)$ & $148(13.4)$ & n.o. & $3(0.3)$ & $4(0.4)$ & $6(0.5)$ & n.o. & n.o. & n.o. \\
\hline S8 & $60(5.4)$ & n.o. & n.o. & $1(0.9)$ & $3(0.3)$ & 11(1) & n.o. & n.o. & $2(0.2)$ \\
\hline
\end{tabular}

Note: n.o.: was not observed

Table 5. Sites' levels of pollution by formaldehyde, hydrogen fluoride and nitrogen dioxide and land-use cover

\begin{tabular}{lccccccccc}
\hline \multirow{2}{*}{ Site } & \multicolumn{3}{c}{ Level of pollution } & \multicolumn{5}{c}{ Land-use cover, \% } \\
\cline { 2 - 9 } $\mathbf{N O}_{2}$ & HF & Formaldehyde & TBG & TCG & TBG+TCG & Ind & R \\
\hline S1 & + & +++ & + & 16.85 & 0.1 & 16.95 & 7.4 & 33.3 \\
S2 & ++ & +++ & +++ & 22.6 & 0.35 & 22.95 & 5.8 & 15 \\
S3 & - & - & + & 38.15 & 8.87 & 47.02 & 0 & 0.78 \\
S4 & +++ & - & ++++ & 22.69 & 0.1 & 22.79 & 2.52 & 18.4 \\
S5 & + & - & + & 57.70 & 6.16 & 63.86 & 3.4 & 0.2 \\
S6 & +++ & + & ++++ & 16.50 & 0.37 & 16.87 & 0 & 16.4 \\
S7 & +++ & - & ++++ & 26.90 & 0.01 & 26.91 & 4.64 & 9.45 \\
S8 & - & - & ++ & 17.17 & 25.36 & 42.53 & 0 & 0.38 \\
\hline
\end{tabular}

Note: -: pollutant is not detected, + low level of pollutant (n, \% < $5 \%),++$ middle level of pollutant $(5 \% \leq \mathrm{n}, \%<10 \%),+++$ high level of pollutant $(10 \% \leq n, \%)$

Table 5 shows that Sites S1, S3, and S5 were the least contaminated with formaldehyde. The greatest number of times the excess of MPC for formaldehyde was found at Sites S4, S6, and S7 (see Table 5). Sites S5 and S3 were characterized by the largest greening cover, $47.2 \%$, and $63.86 \%$, respectively. The excesses of the MPC for HF were often observed only at two Sites S1 and S2 (see Table 5). In Site S6 it was only one time during investigated period (see Table 4).

Most often, MPC excesses for $\mathrm{NO}_{2}$ were observed at Sites S4, S6, and S7. They are located near the largest metallurgical enterprises. Excesses were not detected at Site S3 and S8. These sites are located in the residential area. They were characterized by high greening cover. Site S5 had dominated broadleaved greening cover. At Site S8, there was a more coniferous greening than broadleaved one. However, both sites were characterized by the least pollution of the air.

\section{Discussion}

Chelyabinsk showed heavy air pollution, having about $30 \%$ of pollution days in the whole year. According to results there were three the most dangerous air pollutants in Chelyabinsk: formaldehyde, $\mathrm{HF}$, and $\mathrm{NO}_{2}$. Cases of high atmospheric air pollution for other pollutants were rare.

It can be concluded that there is no specific source of formaldehyde in the city because every Transport is one of the sources of formaldehyde air pollution. Also, formaldehyde can be formed as a result of photochemical reactions with nitrogen oxides and ozone from hydrocarbons emitted by industrial enterprises There are cancer and non-cancer effects after exposure to formaldehyde at atmospheric air. Different types of cancer are caused by formaldehyde but they appear at a high level of formaldehyde. The non-cancer effects include asthma, allergy, shortness, and sensory irritation to the eyes. They may occur at low concentrations of formaldehyde. It is well known that plants absorb formaldehyde by leaves and metabolize it in the Calvin cycle by two-step enzymatic oxidation (Kim et al. 2010). In Chelyabinsk urban area the times of exceeded MPC of the formaldehyde during 20162019 were the smallest for areas characterized by high greening cover.

It can be assumed that the metallurgical industry was the source of HF. However, the sites of excess concentration are located in different parts of the city, and studying the causes of this phenomenon requires additional research. In this study, there was no relationship between land-use and HF concentration. It should be noted that ground-level concentration of urban air pollutants is function of emissions, weather conditions, terrain, photochemical transformations, urban building, and other factors.

Metallurgical enterprises emit $\mathrm{NO}_{2}$, called the foxtail gas. To a lesser extent, for Chelyabinsk, nitrogen dioxide can be considered as traffic-related air pollutant. Ecotoxicological studies have shown that prolonged nitrogen dioxide exposures can cause decreases in lung host defenses and changes in lung structure (Kado et al. 2007). The previous studies have shown the associations of land cover types with air pollution from $\mathrm{NO}_{2}$ (Guo et al. 2019). Our study also showed that areas with higher greening cover had lower concentrations of $\mathrm{NO}_{2}$. There was no effect of the type of greening on the contamination of formaldehyde and $\mathrm{NO}_{2}$.

Finally, we did not find any associations of the industrial and residential land-use with formaldehyde, HF, and $\mathrm{NO}_{2}$ concentrations. There was an influence of urban greening on air pollution in the studied four years. It should be noted that urban greening is a win-win solution to Chelyabinsk urban air pollution but, of course, direct way to improve urban air quality is decreasing industrial and transport emissions. 


\section{ACKNOWLEDGEMENTS}

This research was funded by the Ministry of Science and Higher Education of the Russian Federation (Grant No. FENU-2020-0022).

\section{REFERENCES}

Abhijith KV, Kumar P, Gallagher J et al. 2017. Air pollution abatement performances of green infrastructure in open road and built-up street canyon environments - A review (2017). Atmospher Environ 162: 71-86.

Buccolieri R, Jeanjean APR, Gatto E, Leigh RJ. 2018. The impact of trees on street ventilation, NOx and PM2.5 concentrations across heights in Marylebone Rd street canyon, central London. Sustain Cities Soc 41: 227-241.

Gou Y, Su JG, Dong Y, Wolch J. 2019. Application of land use regression techniques for urban greening: An analysis of Tianjin, China. Urban For Urban Green 38: 11-21. DOI: 10.1016/j.ufug.2018.10.013.

Han D, Shen H, Duan W, Chen L. 2020. A review on particulate matter removal capacity by urban forests at different scales. Urban For Urban Green 48: 126565. DOI: 10.1016/j.ufug.2019.126565.

Kado N. 2007. Review of the California Ambient Air Quality Standard For Nitrogen Dioxide. California Environmental Protection Agency, San Fransisco.

Kim KJ, Jeong MIl, Lee DW et al. 2010. Variation in formaldehyde removal efficiency among indoor plant species. HortScience 45 (10): 1489-1495.

Klingberg J, Broberg M, Strandberg B, Thorsson P, Pleijel H. 2017. Influence of urban vegetation on air pollution and noise exposure - A case study in Gothenburg, Sweden. Sci Total Environ 599-600: 17281739.
Krupnova TG, Mashkova IV, Kostryukova AM. 2017. Using birch leaves to indicate air pollution. Intl J Geomate 13 (40): 54-59.

Krupnova TG, Mashkova IV, Gavrilkina SV, Scalev ED, Egorov NO. 2018. Concentrations of metal(loid)s in outdoor and indoor dust from Russian City. Intl J Geomate 15 (52): 30-37.

Krupnova TG, Rakova OV, Mashkova IV, Artyukov EV, Vlasov NE. 2019. Health risk assessment of metal(loid)s exposure via indoor dust from urban areas in Chelyabinsk, Russia. Intl J Geomate 16 (55): 1-7.

Ministry of Ecology of the Chelyabinsk Region. 2016-2019. http://mineco174.ru

Nowak DJ, Hirabayashi S, Ellis E, Greenfield EJ. 2014. Tree and forest effects on air quality and human health in the United States. Environ Pollut 193: 119-129.

Santiago JL, Rivas E, Sanchez B, Buccolieri R, Martin F. 2017. The impact of planting trees on NOx concentrations: The case of the Plaza de la Cruz neighborhood in Pamplona (Spain). Atmosphere 8 (7): 131.

Taleghani M, Clark A, Swan W, Mohegh A. 2020. Air pollution in a microclimate; the impact of different green barriers on the dispersion. Sci Total Environ 711: 134649.

Theophanides M, Anastassopoulou J, Theophanides T. 2011. Air Polluted Environment and Health Effects. In.: Orosa J (ed.) Indoor and Outdoor Air Pollution. IntechOpen, London.

Zhou Y, Liu H, Zhou J, Xia M. 2019. Simulation of the impact of urban forest scale on PM2.5 and PM10 based on system dynamics. Sustainability (Switzerland) 11 (21): 5998.

Xu X, Xia J, Gao Y, Zheng W. 2020. Additional focus on particulate matter wash-off events from leaves is required: A review of studies of urban plants used to reduce airborne particulate matter pollution. Urban For Urban Green 48: 126559.

Xing Y, Brimblecombe P. 2020. Trees and parks as "the lungs of cities". Urban For Urban Green 48: 126552. DOI: 10.1016/j.ufug.2019.126552 